\title{
Produtividade de genótipos de trigo duplo propósito submetidos ao pastejo com vacas em lactação
}

[Productivity of dual-purpose wheat genotypes under grazing with lactating cows]

\author{
M.P. Quatrin ${ }^{1}$, C.J. Olivo ${ }^{1}$, G.R. Meinerz ${ }^{2}$, R.S. Fontaneli ${ }^{3}$, P.F. Aguirre ${ }^{1}$, D.C. Seibt ${ }^{1}$, \\ J.F. Aires ${ }^{1}$,D.R. Falk ${ }^{1}$, C.P. Sauter ${ }^{1}$, A.R. Silva ${ }^{1}$ \\ ${ }^{1}$ Universidade Federal de Santa Maria - UFSM - Santa Maria, RS \\ ${ }^{2}$ Universidade Federal da Fronteira Sul - UFFS - Cerro Largo, RS \\ ${ }^{3}$ Empresa Brasileira de Pesquisa Agropecuária - Embrapa Trigo - Passo Fundo, RS
}

\begin{abstract}
RESUMO
Esta pesquisa foi conduzida com o objetivo de avaliar a produtividade de dois genótipos de trigo de duplo propósito, BRS Tarumã e BRS Umbu, submetidos ao pastejo com vacas em lactação. O delineamento experimental foi o inteiramente ao acaso, com dois tratamentos (genótipos), três repetições (piquetes) e medidas repetidas no tempo (pastejos). Avaliaram-se a precocidade, a composição estrutural dos trigos, as produções de forragem e de biomassa de lâminas foliares, as taxas de acúmulo diário de forragem e de lâminas foliares, a taxa de lotação, as ofertas de forragem e de lâminas foliares, a eficiência de pastejo, o consumo aparente e a produção de grãos. O trigo mais precoce para produção de forragem foi o BRS Umbu. Houve diferença para a produção de forragem (3196 vs. $4143 \mathrm{~kg} \mathrm{MS} / \mathrm{ha}$ ) e de lâminas foliares (2281 vs. 3205kg MS/ha) para os genótipos BRS Umbu e BRS Tarumã, respectivamente. Valores similares foram encontrados para taxa de lotação (2,26UA/ha); eficiência de pastejo $(52,26 \%)$, consumo aparente $(2,91 \%)$ e produção de grãos $(1716 \mathrm{~kg} / \mathrm{ha})$. O genótipo BRS Tarumã é o mais indicado para o manejo de duplo propósito em condições de pastejo com vacas em lactação.
\end{abstract}

Palavras-chave: cereais de inverno, forragem, grãos, Triticum aestivum

\begin{abstract}
The objective of this research was to evaluate the productivity of two dual-purpose wheat genotypes BRS Tarumã and BRS Umbu under grazing with lactating cows. The experimental design was completely randomized, with two treatments, three replications (paddocks) and repeated measures (grazing cycles). Studied variables were early growth, the structural composition of wheat, forage production, leaf blade biomass, the stocking rate, the herbage and leaf blade allowance, the grazing efficiency, the herbage intake and grain yield. The earliest genotype for forage production was the BRS Umbu. Differences in herbage yield between BRS Umbu and BRS Tarumã genotypes (3196 vs. 4143kg DM/ha) and leaf blade production (2281 vs. 3205kg DM/ha), respectively, were detected. Similar values between cultivars were found in stocking rate (2,26AU/ha); grazing efficiency (52,26\%), herbage intake (2,91 \%) and grain yield $(1716 \mathrm{~kg} / \mathrm{ha})$. The BRS Tarumã genotype is the most suitable for dual-purpose under grazing with dairy cows.
\end{abstract}

Keywords: winter cereal, forage, grain, Triticum aestivum

Recebido em 26 de setembro de 2016

Aceito em 3 de dezembro de 2016

*Autor para correspondência (corresponding author)

E-mail: clairolivo@yahoo.com.br 


\section{INTRODUÇÃO}

A região Sul apresenta grande potencial de produção de forragem. Há, no entanto, períodos críticos, especialmente entre o outono e o início do inverno. Nessa época, há um declínio natural na produção e na qualidade de espécies de ciclo estival e, normalmente, forrageiras mais utilizadas, como o azevém, de ciclo hibernal mais tardio, ainda não têm condições de uso. Uma alternativa para cobrir esse déficit de forragem é o cultivo de trigo de duplo propósito, de produção mais precoce em relação ao azevém (Ferraza et al., 2013). Ressalta-se que, além da produção de forragem, o pastejo pode contribuir para a elevação da produtividade de grãos, quando comparado ao trigo não pastejado, devido à sua alta capacidade de perfilhamento, à emissão de novas folhas e ao seu menor porte, que possibilita maior aproveitamento da luz solar (Santos e Fontaneli, 2006). Nesse sentido, vários estudos têm sido conduzidos com cultivares de trigo de duplo propósito, constatando-se a viabilidade do uso dessas variedades para a produção de forragem de alta qualidade durante o seu período vegetativo e, após o seu diferimento, ainda, de silagem ou de grãos (Fontaneli, 2007).

Os cultivares recomendados pela Empresa Brasileira de Pesquisa Agropecuária (EMBRAPA TRIGO - Passo Fundo/RS) para produção de forragem e grãos na região Sul do Brasil são o BRS Guatambu, BRS Figueira, BRS Tarumã e BRS Umbu (Wendt et al., 2006). Dentre esses materiais, o cultivar BRS Tarumã se destaca pelo intenso afilhamento e pela maior resistência às doenças (Fontaneli, 2007), enquanto o BRS Umbu destaca-se pelo ciclo mais precoce e pela maior produção de grãos (Meinerz et al., 2012). No entanto, há poucos estudos que avaliam esses cultivares em condições de pastejo com vacas em lactação, além de eles terem sido conduzidos em regiões específicas.

Nesse contexto, demanda-se a necessidade de experimentações em outras regiões, especialmente, em condições de pastejo. Assim, esta pesquisa teve como objetivo avaliar a produtividade de forragem e de grãos de genótipos de trigo de duplo propósito BRS Umbu e BRS Tarumã em condições de pastejo com vacas em lactação.

\section{MATERIAL E MÉTODOS}

$\mathrm{O}$ experimento foi conduzido entre abril e outubro de 2014, em área pertencente ao Laboratório de Bovinocultura de Leite da Universidade Federal de Santa Maria, localizada na região da Depressão Central do Rio Grande do Sul, com altitude média de $95 \mathrm{~m}$, latitude $29^{\circ}$ $43^{\prime}$ sul e longitude $53^{\circ} 42^{\prime}$ oeste.

O solo da área experimental é classificado como Argissolo Vermelho distrófico arênico, pertencente à unidade de mapeamento São Pedro (Sistema..., 2006). As médias de temperatura e precipitação para o período experimental foram de $17,34^{\circ} \mathrm{C}$ e $194,28 \mathrm{~mm}$, superiores às normais climatológicas para a região, que são de $15,76^{\circ} \mathrm{C}$ e $140,51 \mathrm{~mm}$ (Fig. 1). Para a avaliação experimental, foi utilizada uma área de $4380 \mathrm{~m}^{2}$, subdividida em seis piquetes, com uma área média de $730 \mathrm{~m}^{2}$ cada.

Os tratamentos foram constituídos por dois genótipos de trigo de duplo propósito de utilização, BRS Tarumã e BRS Umbu, submetidos ao pastejo com vacas em lactação. $\mathrm{O}$ delineamento experimental foi o inteiramente ao acaso, com dois tratamentos (genótipos), três repetições de área (piquetes) e medidas repetidas no tempo (pastejos).

Aproximadamente 90 dias antes da semeadura, foi realizada a correção da acidez do solo, com calcário dolomítico, mediante incorporação ao solo com o auxílio de grade aradora. No momento da semeadura, foram utilizados $20 \mathrm{~kg}$ de N/ha, $60 \mathrm{~kg} / \mathrm{ha}$ de $\mathrm{P}_{2} \mathrm{O}_{5}$ e $40 \mathrm{~kg} / \mathrm{ha}$ de $\mathrm{K}_{2} \mathrm{O}$. As adubações fosfórica e potássica, bem como a correção da acidez, seguiram as recomendações da Comissão Brasileira de Química e Fertilidade do Solo- RS/SC (Manual..., 2004) para gramíneas anuais de estação fria.

A semeadura das culturas foi realizada no dia 17 de abril de 2014, com espaçamento entre linhas de $17 \mathrm{~cm}$. A densidade de semeadura preconizada foi de 400 sementes viáveis por $\mathrm{m}^{2}$, com preparo convencional do solo. A adubação de cobertura, à base de ureia, foi de $130 \mathrm{~kg}$ de N/ha, dividida igualmente em quatro aplicações. A primeira aplicação foi realizada 30 dias após a semeadura em função do perfilhamento, e as restantes após cada pastejo. 


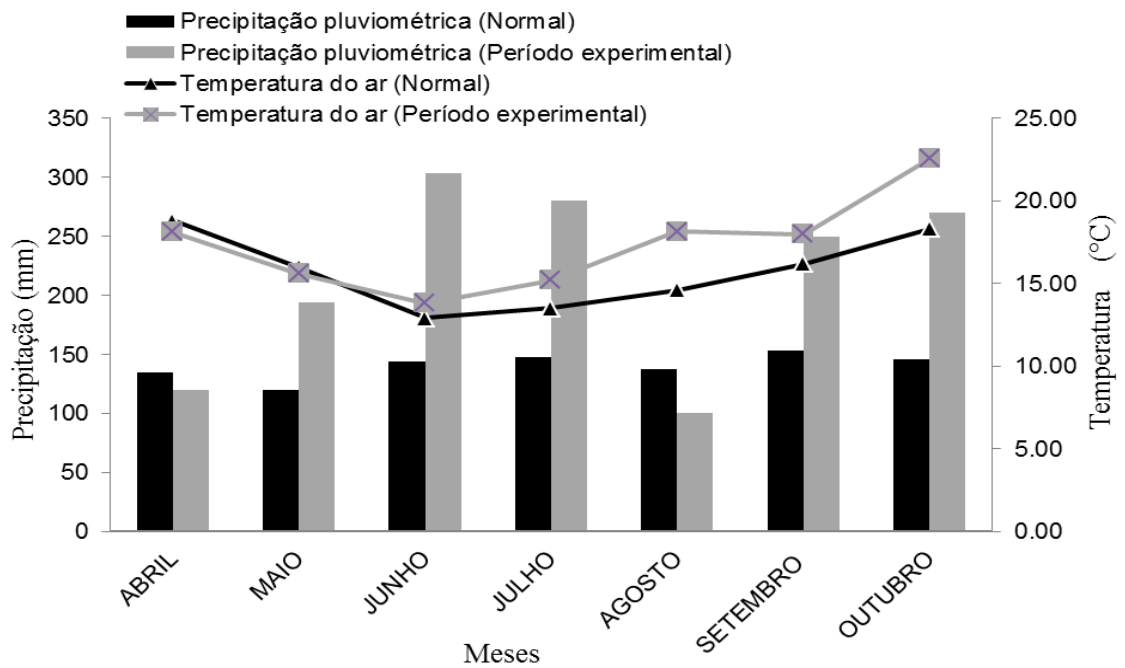

Figura 1. Normais climatológicas e do período experimental (abril a outubro) para precipitação pluviométrica e temperatura do ar. Santa Maria, 2014.

O critério para o início do pastejo foi a altura do dossel, entre 25 e $30 \mathrm{~cm}$. Anteriormente à entrada e após a saída dos animais dos piquetes, mensurou-se a altura da pastagem e fez-se a coleta de amostras da forragem, valendo-se de técnica com dupla amostragem, adaptada de T'mannetje (2000), sendo efetuados cinco cortes rente ao solo e 20 estimativas visuais. A forragem das amostras cortadas no pré e póspastejo foi homogeneizada, e retirou-se uma subamostra para determinação da composição estrutural dos trigos, por meio da separação da lâmina foliar, do colmo+bainha e do material senescente. Esses componentes foram secos em estufa com ar forçado a $55^{\circ} \mathrm{C}$ até atingirem peso constante, para determinação dos teores de matéria parcialmente seca, calculando-se, a seguir, a massa de cada componente.

O método de pastejo foi o de lotação rotacionada, com um dia de ocupação, utilizando-se, para tanto, vacas em lactação da raça Holandesa com peso médio de $570 \mathrm{~kg}$. Os animais foram submetidos a duas ordenhas diárias, às $7 \mathrm{~h} 30$ e às $16 \mathrm{~h}$, e permaneceram nas pastagens de trigo das $9 \mathrm{~h}$ às $15 \mathrm{~h} 30 \mathrm{e}$ das $18 \mathrm{~h}$ às 7h. Como complementação alimentar, cada animal recebeu, aproximadamente, $1 \mathrm{~kg}$ de concentrado para cada cinco litros de leite. Fora das áreas experimentais, as vacas foram mantidas em pastagens de azevém (Lolium multiflorum Lam.), com mesmo manejo de complementação alimentar.
A produção de forragem foi obtida somando-se o acúmulo de forragem de cada ciclo de pastejo. A taxa de acúmulo foi calculada pela diferença entre a massa de forragem ao pré-pastejo e a massa de forragem residual (pós-pastejo) do pastejo anterior, dividindo-se esse resultado pelo número de dias de intervalo entre pastejos. A carga animal foi calculada com base na oferta de forragem, sendo de $6 \%(6 \mathrm{~kg}$ de forragem seca por $100 \mathrm{~kg}$ de peso corporal). Para o cálculo da taxa de lotação, dividiu-se a carga animal pelo número de dias do ciclo de pastejo. A eficiência de pastejo foi estimada por meio da subtração das massas de forragem inicial e residual, dividindo-se esse valor pela massa de forragem inicial do período, multiplicando-se o resultado por 100. O consumo aparente de forragem foi estimado pela subtração entre a massa de forragem residual da inicial, dividindo-se $\mathrm{o}$ resultado pela carga animal instantânea e multiplicando-se o valor por 100 .

Em cada pastejo, foi monitorada a altura do primeiro nó do colmo, que corresponde ao meristema apical. Quando este atingiu aproximadamente a altura de $10 \mathrm{~cm}$, os pastejos foram interrompidos, e as pastagens diferidas, o que permitiu que as culturas viessem a produzir grãos.

Para a estimativa da produção de grãos, foram coletadas manualmente, em cada piquete, cinco amostras em uma área de $2 \mathrm{~m}^{2}$ cada. Essas amostras foram trilhadas determinando-se, para 
cada piquete, o rendimento de grãos, o peso do hectolitro e a massa de mil grãos ajustados para umidade padrão de $13 \%$.

Os resultados foram submetidos à análise de variância usando-se o teste $\mathrm{F}$ de Fisher-Snedecor para comparação dos dois cultivares. Para a comparação entre os ciclos de pastejo, foi empregado o teste de Tukey a 5\% de probabilidade de erro. Para análise, utilizou-se o procedimento MIXED do pacote estatístico SAS. $\mathrm{O}$ modelo estatístico referente às variáveis foi: $\mathrm{Yijk}=\mathrm{m}+\mathrm{Ti}+\mathrm{Rj}(\mathrm{Ti})+\mathrm{Pk}+(\mathrm{TP}) \mathrm{ik}+\varepsilon_{\mathrm{ijk}}, \mathrm{em}$ que Yijk representa as variáveis dependentes; $\mathrm{m}$ é a média de todas as observações; Ti é o efeito dos tratamentos (genótipos); $\mathrm{Rj}(\mathrm{Ti}$ ) é o efeito de repetição dentro dos tratamentos (erro a); Pk é o efeito dos pastejos; (TP)ik representa a interação entre os tratamentos e pastejos; Eijk é o efeito residual (erro b)

O projeto experimental foi aprovado pelo Comitê de Ética e Biossegurança da UFSM, pelo parecer $113 / 2011$, sob o protocolo no $23081016073 / 2011$.

\section{RESULTADOS E DISCUSSÃO}

Seguindo-se a metodologia, na qual se permitiu a utilização das plantas com condição limite do primeiro nó, a cerca de $10 \mathrm{~cm}$ do solo, foram conduzidos três ciclos de pastejo, com ambos os genótipos, nos meses de junho, julho e agosto de 2014. Observa-se que a altura (Tab. 1) ficou dentro do proposto na metodologia para ambos os genótipos.

Para a massa de forragem (pré-pastejo), foram encontradas diferenças $(\mathrm{P} \leq 0,05)$ entre os genótipos no segundo e no terceiro pastejo, com valores superiores para o trigo BRS Tarumã. Esse resultado se deve às características estruturais desse cultivar, que apresenta maior $(\mathrm{P} \leq 0,05)$ biomassa de lâminas foliares em relação ao cultivar BRS Umbu (Tab. 1). Entre os pastejos, observa-se que o cultivar BRS Umbu manteve a massa de forragem inicial similar, com cerca de $1500 \mathrm{~kg}$ de $\mathrm{MS} / \mathrm{ha}$. Tal fato decorre da menor capacidade de perfilhamento desse cultivar, em relação ao BRS Tarumã (Martin et al., 2010), evidenciada pela menor massa de lâminas foliares ao pré-pastejo para BRS Umbu (Tab. 1).

Tabela 1. Altura do dossel forrageiro, massa de forragem e massa dos componentes estruturais de genótipos de trigo de duplo propósito submetidos ao pastejo com vacas em lactação. Santa Maria, 2014

\begin{tabular}{|c|c|c|c|c|c|c|c|c|c|c|}
\hline \multicolumn{11}{|c|}{ Pastejos } \\
\hline Genótipo & $1^{\circ}$ (jun) & $2^{\circ}(\mathrm{jul})$ & $3^{\circ}$ (ago) & Média & & $1^{\circ}$ (jun) & $2^{\circ}(\mathrm{jul})$ & $3^{\circ}$ (ago) & Média & \multirow{2}{*}{$\mathrm{CV}(\%)$} \\
\hline \multicolumn{7}{|c|}{ Pré-pastejo } & \multicolumn{3}{|c|}{$\begin{array}{l}2 \text { (jui) } 5 \text { (ago) liedia } \\
\text { Pós-pastejo }\end{array}$} & \\
\hline \multicolumn{11}{|c|}{ Altura $(\mathrm{cm})^{*}$} \\
\hline BRS Umbu & 26,4 & 28,2 & 29,4 & 29,3 & - & 11,7 & 10,4 & 13,0 & 11,7 & - \\
\hline BRS Tarumã & 25,7 & 26,8 & 27,1 & 26,5 & - & 9,5 & 9,2 & 9,1 & 9,3 & - \\
\hline \multicolumn{11}{|c|}{ Massa de forragem $(\mathrm{kg} \mathrm{MS} / \mathrm{ha})$} \\
\hline BRS Umbu & $1550 \mathrm{~A}$ & $1460 \mathrm{Ab}$ & $1590 \mathrm{Ab}$ & 1540 & 5,83 & $650 \mathrm{~B}$ & $780 \mathrm{~B}$ & $930 \mathrm{~A}$ & 790 & 8,15 \\
\hline BRS Tarumã & $1570 \mathrm{~B}$ & $1750 \mathrm{Ba}$ & $2070 \mathrm{Aa}$ & 1790 & 5,45 & $660 \mathrm{~B}$ & $690 \mathrm{~B}$ & $1030 \mathrm{~A}$ & 780 & 8,23 \\
\hline CV $(\%)$ & 6,82 & 7,06 & 6,83 & - & - & 10,91 & 9,88 & 7,27 & - & - \\
\hline \multicolumn{11}{|c|}{ Lâmina foliar ( $\mathrm{kg} \mathrm{MS/ha)}$} \\
\hline BRS Umbu & $1140 \mathrm{~A}$ & $887 \mathrm{Bb}$ & $786 \mathrm{Bb}$ & 937 & 7,3 & $257 \mathrm{Ab}$ & $277 \mathrm{~A}$ & $281 \mathrm{~A}$ & 272 & 10,63 \\
\hline BRS Tarumã & $1303 \mathrm{~A}$ & $1333 \mathrm{Aa}$ & $1214 \mathrm{Aa}$ & 1283 & 5,36 & $367 \mathrm{Aa}$ & $254 \mathrm{~A}$ & $307 \mathrm{~A}$ & 309 & 18,12 \\
\hline $\mathrm{CV}(\%)$ & 6,90 & 7,78 & 15,71 & - & - & 15,24 & 17,05 & 15,08 & - & - \\
\hline \multicolumn{11}{|c|}{ Colmo+bainha (kg MS/ha) } \\
\hline BRS Umbu & $338 \mathrm{Ba}$ & $442 \mathrm{Ba}$ & 771Aa & $517 \mathrm{a}$ & 5,4 & $248 \mathrm{Ba}$ & $354 \mathrm{AB}$ & $449 \mathrm{~A}$ & 350 & 13,7 \\
\hline BRS Tarumã & $207 \mathrm{Bb}$ & $304 \mathrm{Bb}$ & $535 \mathrm{Ab}$ & $349 b$ & 7,8 & $187 \mathrm{Bb}$ & $254 \mathrm{AB}$ & 406A & 283 & 13,3 \\
\hline $\mathrm{CV}(\%)$ & 14,82 & 10,82 & 15,73 & - & - & 27,15 & 18,33 & 15,56 & - & - \\
\hline \multicolumn{11}{|c|}{ Material senescente (kg MS/ha) } \\
\hline BRS Umbu & $71 B$ & $128 \mathrm{AB}$ & $172 \mathrm{Ab}$ & 124 & 19,8 & $134 \mathrm{~A}$ & $153 \mathrm{~A}$ & $202 \mathrm{Ab}$ & 163 & 11,68 \\
\hline BRS Tarumã & $58 \mathrm{~B}$ & $112 B$ & 319Aa & 163 & 18,6 & $103 \mathrm{~B}$ & 149B & $307 \mathrm{Aa}$ & 186 & 10,69 \\
\hline CV $(\%)$ & 15,37 & 15,46 & 15,70 & - & - & 25,45 & 20,25 & 15,73 & - & - \\
\hline
\end{tabular}

Médias seguidas por letras distintas, maiúsculas na linha e minúsculas na coluna, diferem entre si a $5 \%$ de probabilidade de erro; $*=$ dados não analisados estatisticamente. 
Em relação à massa de lâminas foliares, os valores foram similares na primeira avaliação, no entanto, no segundo e no terceiro pastejo, os valores de biomassa de lâminas foliares foram maiores $(\mathrm{P} \leq 0,05)$ para o trigo BRS Tarumã. Destaca-se também que esse genótipo apresenta valores mais equilibrados entre os ciclos de pastejo. Esse resultado se deve à intensa capacidade de afilhamento e ao hábito de crescimento mais prostrado desse genótipo (Fontaneli, 2007), o que resulta em alongamento reduzido de seus entrenós e aumenta, consequentemente, a massa do componente lâmina foliar. Também Hastenpflug et al. (2011), ao avaliarem cultivares de trigo duplo propósito no estado do Paraná, observaram que o genótipo BRS Tarumã apresenta maior relação percentual de folhas na fitomassa total das plantas quando comparado com BRS Umbu.

Quanto à massa de colmo+bainha (pré-pastejo), verificaram-se valores superiores $(\mathrm{P} \leq 0,05)$ para $\mathrm{o}$ trigo BRS Umbu. Esse resultado se deve ao hábito de crescimento mais ereto (Fontaneli, 2007) desse material, que apresenta entrenós de maior comprimento em relação ao trigo BRS Tarumã e, consequentemente, eleva a massa de colmos.

A elevação da massa de colmo+bainha observada ao longo do período de avaliação para ambos os trigos é resultante do avanço do estádio fenológico das plantas, o que as induz a direcionar os fotoassimilados para a formação de estruturas reprodutivas em detrimento das vegetativas, alongando entrenós e consumindo reservas de energia (Machado et al., 2011).

Para o material senescente, foram verificados valores superiores e aumentos mais significativos desse componente ao longo do período de utilização para o genótipo BRS Tarumã, em função da maior mobilização de nutrientes para a formação de tecidos jovens, visto que esse cultivar apresenta intenso perfilhamento (Martin et al., 2010).

Para a massa de forragem do resíduo, os dados guardam relação com os valores de disponibilidade de forragem (pré-pastejo), havendo aumento na terceira avaliação para os dois cultivares. Comportamento similar ocorreu com as frações colmo+bainha e material senescente.

Com base nas avaliações realizadas (Tab. 2), confirma-se que o BRS Umbu é mais precoce que o BRS Tarumã, levando-se mais tempo $(\mathrm{P} \leq 0,05)$ para se efetuar o primeiro pastejo, considerando-se o critério utilizado para o início dos pastejos (altura do pasto). Essa característica de o BRS Tarumã ser mais tardio está associada com a forte sensibilidade às temperaturas vernalizantes para o início da floração. No Brasil, o total de dias com temperaturas vernalizantes durante o ano não é tão alto se comparado a regiões de clima temperado, assim os trigos com alta exigência em frio, como o BRS Tarumã, alongam seu ciclo (Alberto et al., 2009). Um ciclo mais longo possibilita maior produção de forragem e de lâminas foliares mediante maior contribuição de perfilhos. Trabalhos conduzidos na região da Depressão Central do Rio Grande do Sul por Meinerz et al. (2012), ao avaliarem distintos cultivares submetidos a três cortes, confirmam a maior produção média de lâminas foliares do BRS Tarumã, sendo de $2512 \mathrm{~kg} \mathrm{MS} / \mathrm{ha}$, quando comparado ao BRS Umbu, com $1509 \mathrm{~kg} \mathrm{MS} / \mathrm{ha}$. Comparando-se os cultivares, destaca-se que a contribuição de lâminas foliares na massa de forragem total foi maior no trigo BRS Tarumã, sendo de $78 \%$, enquanto no BRS Umbu foi de $68 \%$.

Para a taxa de acúmulo de forragem, houve similaridade entre os genótipos. Entre os ciclos de pastejo, houve aumento $(\mathrm{P} \leq 0,05)$ da taxa de acúmulo diário de forragem na terceira avaliação, nos dois genótipos, condição associada ao aumento da participação de colmo+bainha (Tab. 1). Nesse período, há elevação da temperatura ambiente, que estimula a elongação dos entrenós das plantas de ciclo hibernal (Grise et al., 2001), o que faz com que elas atinjam a altura preconizada para o início da utilização em menos tempo e, assim, seja reduzido o intervalo entre um ciclo e outro, elevando-se, consequentemente, a taxa de acúmulo diário de forragem. 
Quatrin et al.

Tabela 2. Produtividade e resposta animal para genótipos de trigo de duplo propósito submetidos ao pastejo com vacas em lactação. Santa Maria, 2014

\begin{tabular}{|c|c|c|c|c|c|}
\hline \multirow{2}{*}{ Genótipo } & \multicolumn{3}{|c|}{ Pastejos } & \multirow{2}{*}{ Total*/Média } & \multirow{2}{*}{ CV (\%) } \\
\hline & $1^{\circ}$ (jun) & $2^{\circ}$ (jul) & $3^{\circ}$ (ago) & & \\
\hline \multicolumn{6}{|c|}{ Tempo de cada ciclo de pastejo (dias) } \\
\hline BRS Umbu & $49 \mathrm{Ab}$ & $28 \mathrm{~B}$ & $18 \mathrm{Cb}$ & 32 & 2,21 \\
\hline BRS Tarumã & $54 \mathrm{Aa}$ & $29 B$ & $25 \mathrm{Ca}$ & 36 & 3,99 \\
\hline $\mathrm{CV}(\%)$ & 4,23 & 3,84 & 2,84 & - & - \\
\hline \multicolumn{6}{|c|}{ Produção de forragem (kg MS/ha) } \\
\hline BRS Umbu & $1551 \mathrm{~A}$ & $810 \mathrm{Bb}$ & $837 \mathrm{Bb}$ & $3196 b^{*}$ & 7,69 \\
\hline BRS Tarumã & $1681 \mathrm{~A}$ & $1091 \mathrm{Ba}$ & $1370 \mathrm{Ba}$ & $4143 a^{*}$ & 6,75 \\
\hline $\mathrm{CV}(\%)$ & 8,25 & 5,26 & 11,26 & - & - \\
\hline \multicolumn{6}{|c|}{ Produção de biomassa de lâminas foliares (kg MS/ha) } \\
\hline BRS Umbu & $1140 \mathrm{~A}$ & $629 \mathrm{Bb}$ & $511 \mathrm{Bb}$ & $2281 b^{*}$ & 9,80 \\
\hline BRS Tarumã & $1303 \mathrm{~A}$ & $965 \mathrm{Aa}$ & $935 \mathrm{Aa}$ & $3205 a^{*}$ & 7,65 \\
\hline $\mathrm{CV}(\%)$ & 10,38 & 7,97 & 14,53 & - & - \\
\hline \multicolumn{6}{|c|}{ Taxa de acúmulo diário de forragem (kg MS/ha/dia) } \\
\hline BRS Umbu & $31,20 \mathrm{~B}$ & $28,21 \mathrm{~B}$ & $46,45 \mathrm{~A}$ & 35,29 & 12,71 \\
\hline BRS Tarumã & $31,34 \mathrm{~B}$ & $36,84 \mathrm{~B}$ & $54,16 \mathrm{~A}$ & 40,78 & 12,38 \\
\hline $\mathrm{CV}(\%)$ & 7,03 & 6,64 & 15,73 & - & - \\
\hline \multicolumn{6}{|c|}{ Taxa de acúmulo diário de lâminas foliares ( $\mathrm{kg} \mathrm{MS/ha/dia)}$} \\
\hline BRS Umbu & $22,85 \mathrm{~B}$ & $21,98 \mathrm{Bb}$ & $28,07 \mathrm{~A}$ & 24,30 & 9,33 \\
\hline BRS Tarumã & $24,29 \mathrm{~B}$ & $32,60 \mathrm{Aa}$ & $37,00 \mathrm{~A}$ & 31,30 & 8,35 \\
\hline $\mathrm{CV}(\%)$ & 8,69 & 9,13 & 8,52 & - & - \\
\hline \multicolumn{6}{|c|}{ Taxa de lotação (UA/ha/dia) } \\
\hline BRS Umbu & $1,29 \mathrm{~B}$ & $1,78 \mathrm{~B}$ & $3,69 \mathrm{~A}$ & 2,25 & 10,27 \\
\hline BRS Tarumã & $1,43 \mathrm{~B}$ & $2,18 \mathrm{~B}$ & $3,23 \mathrm{~A}$ & 2,28 & 10,15 \\
\hline $\mathrm{CV}(\%)$ & 20,83 & 14,31 & 8,20 & - & - \\
\hline \multicolumn{6}{|c|}{ Oferta real de forragem ( $\mathrm{kg} \mathrm{MS} / 100 \mathrm{~kg} \mathrm{PC})$} \\
\hline BRS Umbu & $5,50 \mathrm{~A}$ & $6,45 \mathrm{~A}$ & $5,53 \mathrm{~A}$ & 5,78 & 5,47 \\
\hline BRS Tarumã & $4,55 \mathrm{~B}$ & $6,09 \mathrm{~A}$ & $5,61 \mathrm{~A}$ & 5,40 & 6,33 \\
\hline $\mathrm{CV}(\%)$ & 7,50 & 6,40 & 7,88 & - & - \\
\hline \multicolumn{6}{|c|}{ Oferta de lâminas foliares (kg MS/100 kg PC) } \\
\hline BRS Umbu & $3,99 \mathrm{~A}$ & $3,85 \mathrm{~A}$ & $2,73 \mathrm{~B}$ & 3,90 & 7,92 \\
\hline BRS Tarumã & $3,78 \mathrm{~B}$ & $4,64 \mathrm{~A}$ & $3,29 \mathrm{C}$ & 3,53 & 6,62 \\
\hline $\mathrm{CV}(\%)$ & 8,10 & 7,46 & 10,53 & - & - \\
\hline \multicolumn{6}{|c|}{ Eficiência de pastejo (\% da massa de forragem inicial) } \\
\hline BRS Umbu & $57,85 \mathrm{~A}$ & $47,22 \mathrm{AB}$ & $42,44 \mathrm{~B}$ & 48,76 & 7,72 \\
\hline BRS Tarumã & $57,63 \mathrm{~A}$ & $59,78 \mathrm{~A}$ & $49,79 \mathrm{~A}$ & 55,77 & 7,17 \\
\hline $\mathrm{CV}(\%)$ & 7,79 & 8,62 & 11,76 & - & - \\
\hline \multicolumn{6}{|c|}{ Consumo aparente $(\% \mathrm{PC})$} \\
\hline BRS Umbu & $3,14 \mathrm{~A}$ & $2,94 \mathrm{~A}$ & $2,34 \mathrm{~B}$ & 2,80 & 8,15 \\
\hline BRS Tarumã & $2,62 \mathrm{~A}$ & $3,67 \mathrm{~A}$ & $2,84 \mathrm{~A}$ & 3,02 & 8,55 \\
\hline $\mathrm{CV}(\%)$ & 9,20 & 8,68 & 14,42 & - & - \\
\hline
\end{tabular}

Médias seguidas por letras distintas, maiúsculas na linha e minúsculas na coluna, diferem entre si a $5 \%$ de probabilidade de erro; *= produção total; $\mathrm{PC}=$ peso corporal.

Para taxa de acúmulo diário de lâminas foliares, houve variabilidade $(\mathrm{P} \leq 0,05)$ entre genótipos no segundo pastejo, com valor mais elevado para o trigo BRS Tarumã. Ao avaliarem diferentes cereais de inverno de duplo propósito submetidos a três cortes, Meinerz et al. (2012) verificaram superioridade para o genótipo BRS Tarumã em relação ao BRS Umbu para a taxa de acúmulo diário de lâminas foliares apenas no segundo corte, sendo de $30 \mathrm{~kg}$ de $\mathrm{MS} / \mathrm{ha}$ 'dia. Observa-se 
que o genótipo BRS Tarumã apresenta maior estabibilidade na taxa de acúmulo de lâminas foliares do segundo para o terceiro pastejo, se comparado ao BRS Umbu. O comportamento observado deve-se ao ciclo tardio-precoce desse material, considerado por Walter et al. (2009) como muito longo. Essa característica confere ao BRS Tarumã intenso perfilhamento, o que possibilita maior contribuição de lâminas foliares provenientes dos perfilhos até o final do período de avaliação. Tal fato não ocorre com o trigo BRS Umbu de ciclo semitardio e hábito de crescimento mais ereto (Fontaneli, 2007), o qual inicia a fase de elongação do colmo precocemente e, assim, reduz a emissão de lâminas foliares, como verificado pela menor biomassa de lâminas foliares e maior de colmo+bainha com o trigo BRS Umbu na massa de forragem inicial.

Com relação à taxa de lotação, não foram observadas diferenças entre os genótipos. Observou-se entre eles um incremento nas taxas de lotação $(\mathrm{P} \leq 0,05)$ do segundo para o terceiro pastejo. Esse aumento deve-se à maior taxa de acúmulo de forragem. Nesse intervalo, o menor tempo do ciclo de pastejo é resultante da maior elongação dos colmos nesse período, pois isso permite que a altura preconizada para a reentrada dos animais no pasto seja atingida em menos tempo, o que reduz o intervalo de descanso. Taxas de lotação semelhantes foram encontradas por Aguirre et al. (2014) na região da Depressão Central do Rio Grande do Sul, sendo de 2,6UA/ha em pastagens de azevém sob cultivo extreme e sobressemeadas em Coastcross- 1 .

Quanto à oferta real de forragem, houve similaridade entre os genótipos ao longo dos pastejos, mantendo-se próxima à proposta na metodologia (6\%). Ofertas de forragem similares às do presente estudo foram observadas por Quatrin et al. (2015), de $4,47 \%$ e $6,34 \%$ no início e ao longo dos ciclos de pastejo, respectivamente, em pastagens de azevém manejadas com vacas em lactação. A oferta de lâminas foliares foi semelhante entre os trigos, havendo decréscimo esperado no terceiro ciclo de pastejo.
Com relação à eficiência de pastejo, houve similaridade entre os trigos. Entre os pastejos, houve redução para o BRS Umbu, atribuída à maior participação de colmos na massa de forragem (Tab. 1). Na média dos pastejos, os valores observados foram similares e próximos a $50 \%$ para ambos os trigos. De acordo com Parsons e Chapman (2000), valores de eficiência de pastejo próximos a $50 \%$ possibilitam a maximização do rendimento de forragem colhida por unidade de área. Delagarde et al. (2001) afirmam que, quando a eficiência de pastejo ultrapassa $50 \%$, ocorrem fortes reduções no consumo individual dos animais.

Para o consumo aparente, houve similaridade entre os genótipos. Entre os ciclos de pastejo, verificou-se que os valores foram similares para o BRS Tarumã enquanto para o BRS Umbu houve declínio $(\mathrm{P} \leq 0,05)$ no terceiro pastejo, condição atribuída à menor massa de lâminas foliares e à maior massa de colmos nesse período (Tab. 1). Já a estabilidade observada para o consumo aparente no genótipo BRS Tarumã com o decorrer dos ciclos de pastejo deve-se a sua maior exigência em temperaturas vernalizantes para o final da fase vegetativa, o que resulta em um longo subperíodo vegetativo (Walter et al., 2009). Essa característica garante a maior contribuição de perfilhos na massa de forragem, o que mantém mais equilibrada a participação de lâminas foliares no decorrer dos pastejos.

Para o rendimento de grãos (Tab. 3), não houve diferença entre os trigos. Os valores são superiores aos verificados por Mariani et al. (2012), de $1178 \mathrm{~kg} /$ ha, ao trabalharem com trigo BRS Tarumã, submetido a dois pastejos. Entretanto, Meinerz et al. (2012), na mesma região, após três cortes, obtiveram produtividades de 2767 e $3468 \mathrm{~kg} /$ ha para BRS Tarumã e Umbu, respectivamente. Os valores obtidos para o rendimento são considerados baixos e devem-se, especialmente, às condições meteorológicas, com valores de precipitação pluviométrica e de temperatura superiores às normais climatológicas para os meses de setembro e outubro (Fig. 1), período que correspondeu ao enchimento e à maturação dos grãos. 
Tabela 3. Rendimento de grãos, massa de mil grãos e peso do hectolitro ( $\mathrm{PH})$, corrigido para umidade padrão de $13 \%$, de genótipos de trigo de duplo propósito após três ciclos de pastejo com vacas em lactação. Santa Maria, 2014

\begin{tabular}{lccc}
\multicolumn{1}{c}{ Genótipo } & $\begin{array}{c}\text { Rendimento } \\
(\mathrm{kg} / \mathrm{ha})\end{array}$ & $\begin{array}{c}\text { Massa de mil } \\
\text { grãos }(\mathrm{g})\end{array}$ & $\begin{array}{c}\mathrm{PH} \\
(\mathrm{kg} / \mathrm{hl})\end{array}$ \\
\hline BRS Umbu & 1655 & $30,01 \mathrm{a}$ & $74,81 \mathrm{~b}$ \\
BRS Tarumã & 1777 & $25,04 \mathrm{~b}$ & $83,11 \mathrm{a}$ \\
$\mathrm{CV}(\%)$ & 5,71 & 2,23 & 0,73 \\
\hline
\end{tabular}

Médias seguidas por letras distintas, na coluna, diferem entre si a $5 \%$ de probabilidade de erro.

Para massa de mil grãos, os maiores valores $(\mathrm{P} \leq 0,05)$ foram observados com o trigo BRS Umbu. Essa variável pode ser influenciada por condições de temperatura, luminosidade e umidade durante a fase de maturação (Guarienti et al., 2005), mas apresenta forte controle genético, sendo uma característica inerente de cada cultivar (Trindade et al., 2006). Resultados semelhantes ao do presente estudo foram relatados por Fontaneli et al. (2009), que, ao trabalharem com o genótipo BRS Umbu na região de Passo Fundo (RS), obtiveram médias de $31 \mathrm{~g}$ para a massa de mil grãos, enquanto Santos et al. (2011), na mesma região, verificaram com BRS Tarumã, sob manejo de duplo propósito, valores de massa de mil grãos próximos a $27 \mathrm{~g}$.

O genótipo de trigo BRS Tarumã apresentou peso do hectolitro superior $(\mathrm{P} \leq 0,05)$ ao $\mathrm{BRS}$ Umbu. Essa diferença pode ser atribuída ao menor espaço vazio existente entre os grãos de trigo do BRS Tarumã, já que estes são de menor tamanho (Santos et al., 2015) e, assim, comportam maior número de grãos em um mesmo volume.

\section{CONCLUSÕES}

O trigo BRS Umbu apresenta ciclo vegetativo mais precoce. O BRS Tarumã apresenta maior produção de forragem e de biomassa de lâminas foliares e, de forma mais equilibrada, entre os ciclos de pastejo. O desempenho das vacas foi melhor na pastagem do cultivar BRS Tarumã com eficiência de pastejo e consumo aparente de forragem mais estáveis entre os ciclos. Os genótipos apresentam rendimento de grãos similar. O genótipo BRS Tarumã é o mais indicado para o manejo de duplo propósito em condições de pastejo com vacas em lactação, se comparado ao BRS Umbu.

\section{REFERÊNCIAS}

AGUIRRE, P.F.; OLIVO, C.J.; SIMONETTI, G.D. et al. Produtividade de pastagens de Coastcross-1 em consórcio com diferentes leguminosas de ciclo hibernal. Ciênc. Rural, v.44, p.2265-2272, 2014.

ALBERTO, C.M.; STRECK, N.A.; WALTER, L.C. et al. Resposta à vernalização de cultivares brasileiras de trigo. Bragantia, v.68, p.535-543, 2009.

DELAGARDE, R.; PRACHE, S.; D'HOUR, P.; PETIT, M. Ingestion de l'herbe par les ruminants au pâturge. Fourrages, v.166, p.189-212, 2001.

FERRAZZA, J.M.; SOARES, A.B.; MARTIN, T.N. et al. Dinâmica de produção de forragem de gramíneas anuais de inverno em diferentes épocas de semeadura. Ciênc. Rural, v.43, p.1174-1181, 2013.

FONTANELI, R.S. Trigo de duplo propósito na integração lavoura-pecuária. Rev. Plantio Direto, v.99, 2007. Disponível em: http://www.plantiodireto.com.br/?body=cont_int \&id=799. Acesso em: 13 de julho de 2017.

FONTANELI, R.S.; FONTANELI, R.S.; SANTOS, H.P. et al. Rendimento e valor nutritivo de cereais de inverno de duplo propósito: forragem verde e silagem ou grãos, Rev. Bras. Zootec., v.38, p.2116-2122, 2009.

GRISE, M.M.; CECATO, U.; MORAES, A. et al. Avaliação da composição química e da digestibilidade in vitro da mistura aveia IAPAR 61 (Avena strigosa schreb) + Ervilha forrageira (Pisum arvense L.) em diferentes alturas sob pastejo. Rev. Bras. Zootec., v.30, p.659-665, 2001. 
GUARIENTI, E.M.; CIACCO' C.F.; CUNHA, G.R. das. et al. Efeitos da precipitação pluvial, da umidade relativa do ar e de excesso de déficit hídrico do solo no peso hectolitro, no peso de mil grãos e no rendimento de grãos de trigo. Ciênc. Tecnol. Alim., v.25, p.412-418, 2005.

HASTENPFLUG, M.; BRAIDA, J.A.; MARTIN, T.N. et al. Cultivares de trigo duplo propósito submetidos ao manejo nitrogenado e a regimes de corte. Arq. Bras. Med. Vet. Zootec., v.63, p.196-202, 2011.

MACHADO, J.M.; ROCHA, M.G.; MORAES, A.B. et al. Intensidade e freqüência de desfolhação em azevém. Rev. Bras. Agroc., v.17, p.365-374, 2011.

MANUAL de adubação e calagem para os estados do Rio Grande do Sul e Santa Catarina. Porto Alegre: SBCSNRS, 2004. 400p.

MARIANI, F.; FONTANELI, R.S.; VARGAS, L. et al. Trigo de duplo propósito e aveia preta após forrageiras perenes e culturas de verão em sistema de integração lavoura - pecuária. Ciênc. Rural, v.42, p.1752-1757, 2012.

MARTIN, T.N.; SIMIONATTO, C.C.; BERTONCELLI, P. et al. Fitomorfologia e produção de cultivares de trigo duplo propósito em diferentes manejos de corte e densidades de semeadura. Ciênc. Rural, v.40, p.1695-1701, 2010 .

MEINERZ, G.R.; OLIVO, C.J.; FONTANELI, R.S. et al. Produtividade de cereais de inverno de duplo propósito na depressão central do Rio Grande do Sul. Rev. Bras. Zootec., v.41, p.873882, 2012.

PARSONS, A.J.; CHAPMAN, D.F. The principles of pasture growth and utilization. In: HOPKINS, A. (Ed.). Grass: its production \& utilization. 3.ed. Oxford: Blackwell Science, 2000. p.31-89.
QUATRIN, M.P.; OLIVO, C.J.; AGNOLIN, C.A. et al. Efeito da adubação nitrogenada na produção de forragem, teor de proteína bruta e taxa de lotação em pastagens de azevém. Bol. Ind. Anim., v.72, p.21-26, 2015.

SANTOS, H.P.; FONTANELI, R.S. Cereais de inverno de duplo propósito para integração lavoura-pecuária no sul do Brasil. Passo Fundo: Embrapa, 2006. 104p.

SANTOS, H.P.; FONTANELI, R.S.; CAIERÃO, E. et al. Desempenho agronômico de trigo cultivado para grãos e duplo propósito em sistemas de integração lavoura-pecuária. Pesqui. Agropec. Bras., v.46, p.1206-1213, 2011.

SANTOS, H.P.; FONTANELI, R.S.; CASTRO, R.L. et al. Avaliação de trigo para grãos e duplo propósito, sob plantio direto. Rev. Bras. Ciênc. Agrár., v.10, p.43-48, 2015.

SISTEMA brasileiro de classificação de solos. 2.ed. Rio de Janeiro: Embrapa, 2006. 306p.

T'MANNETJE, L. Measuring biomass of grassland vegetation. In: MANNETJE, L'.T.; JONES, R.M. Field and laboratory methods for grass land and animal production research. Cambridge: Cabi, 2000. p.51-178.

TRINDADE, M.G.; STONE, L.F.; HEINEMANN, A.B. et al. Nitrogênio e água como fatores de produtividade do trigo no cerrado. Rev. Bras. Eng. Agric. Amb., v.10, p.2429, 2006.

WALTER, L.D.; STRECK, N.A.; ROSA, T.H. et al. Desenvolvimento vegetativo e reprodutivo de cultivares de trigo e sua associação com a emissão de folhas. Ciênc. Rural, v.39, p.23202326, 2009.

WENDT, W.; DEL DUCA, L.J.A.; CAETANO, V.R. Avaliação de cultivares de trigo de duplo propósito, recomendados para cultivo no estado do Rio Grande do Sul. Pelotas: Embrapa Clima Temperado, 2006. 2.p. (Comunicado Técnico, 137). 